\title{
Electores presentes, ciudadanos ausentes: la democracia mexicana en su laberinto
}

Electors present, citizens absent: Mexican democracy in its labyrinth

\author{
Juan Mora Heredia \\ Margarita Jiménez Badillo
}

\section{Resumen}

México registra un panorama con electores presentes pero ciudadanos ausentes, dadas las limitadas condiciones de bienestar y paz social que garanticen una plena participación política. De esta forma, en este artículo se revisan y describen tres condiciones que hoy día son esenciales para fortalecer una vigorosa actividad ciudadana: pobreza, inseguridad pública y acceso a la sociedad de la información. Que por su debilidad, dificultan el impulso a una comunidad con aspiraciones democráticas y jerarquía ciudadana, por encima de la figura de un elector indolente. Recuperando la esencia misma de la política, alejándola de las rutinas patrimonialistas y clientelares predominantes.

\section{Palabras clave}

Participación Ciudadana; Déficits Democráticos; Pobreza; Inseguridad Pública; Acceso a la Sociedad de la Información.

\begin{abstract}
Mexico registers a panorama with present voters but absent citizens, given the limited conditions of welfare and social peace that guarantee full political participation. In this way, this article reviews and describes three conditions that today are essential to strengthen a vigorous citizen activity: poverty, public insecurity and access to the information society. Promoting a community with democratic aspirations and citizen hierarchy, above the figure of an indolent elector. Recovering the very essence of politics, away from patrimonial routines and predominant clientele.
\end{abstract}

\section{Keywords}

Citizen Participation; Democratic Deficits; Poverty; Public Insecurity; Access to the Information Society. 


\section{Introducción}

México enfrentará en 2018 una coyuntura electoral ${ }^{1}$ de gran calado, que le conducirá a un nuevo alineamiento del espectro de poder, con el fortalecimiento y/o modificación de las fuerzas políticas contendientes. De suyo se puede asegurar la fragmentación será la constante. Resultando dudoso un partido pueda lograr mayoría en el congreso, con lo cual es de esperar el presidente electo cualquiera sea su color partidista, no contará con mayoría parlamentaria.

Dicha circunstancia, lleva a más de un analista a considerar estos procesos electorales cruciales para el país, delineando sus itinerarios de los próximos años en todos los ámbitos. Apreciación que no ponemos en duda, y como sistemáticamente ha venido sucediendo, tendremos una puntual realización de los comicios federales y locales. Sustentado en el amplio despliegue de recursos, humanos, logísticos y administrativos de las instituciones correspondientes. Sin embargo, a pesar de toda esta maniobra electoral no es posible ocultar los adeudos de la democracia mexicana.

Efectivamente, a pesar de las elogiadas virtudes concedidas al proyecto democrático-electoral, obligado es rastrear el ingrediente social y sus repercusiones en la dimensión política. Luego que, si bien referirse a un régimen democrático es pensar en la concurrencia de los diferentes grupos a las áreas de poder institucional vía partidos políticos, parlamentos y gobierno. También lo es las implicaciones del componente estructural en la organización de la vida pública, estimulando valores modernos en términos de formación de identidades políticas, estrategias de intervención ciudadana y la definición de un equilibrado andamiaje legal e institucional.

Al respecto, es de subrayar el modelo democrático mexicano apostó por la ruta del voto para conducir su experiencia de cambio político (BECERRA, SALAZAR y WOLDENBERG, 2000). Para ello, la autonomía y ciudadanización del Instituto Federal Electoral (ahora Instituto Nacional Electoral) desde finales de la década de los ochenta ha sido cardinal. Aunque esta sobrecarga de expectativas y responsabilidades lo haya llevado al límite, al confrontar y verse involucrado con las cuotas partidistas.

\footnotetext{
${ }^{1}$ Una jornada donde estarán en disputa 7 gobiernos estatales (Chiapas, Jalisco, Morelos, Puebla, Tabasco, Veracruz, Yucatán), y la Cd. de México. Aunado a la renovación de la Cámara de Diputados (500), Cámara de Senadores (128), Presidencia de la República, 27 congresos locales y alcaldías en 25 estados.
} 
Estamos en un laberinto donde coexiste un moderno sistema electoral del más alto grado de funcionalidad, con un quehacer político recubierto por añejos valores corporativos y autoritarios (DURAND, 2004). Dando forma a un híbrido político con una reconocida democracia electoral, pero muy lejos de ser un escenario donde libertad e igualdad sean el denominador común permeando a toda la población. Esta democratización inconclusa tiene atrapado al país en una ambigua franja gris (DIAMOND, 2004; LEVITSKY y WAY, 2004; SCHEDLER, 2004). Interregno donde lo viejo muere y lo nuevo aún no logra nacer, avivando un clima de fragilidad gubernamental con acontecimientos del más variado perfil, sin que exista autoridad capaz de regularlos.

El año 2000 fue un punto de inflexión en la vida política de la nación, con la transferencia del mando gubernamental del Partido Revolucionario Institucional (PRI), a una nueva élite política agrupada en el Partido Acción Nacional (PAN). Se abrió una transcendental oportunidad política levantando un amplio júbilo colectivo, pues se consideraba el país ingresaba a una promisoria etapa de modernización institucional. Un par de sexenios después, en medio de una gran amargura por las expectativas no cumplidas, el partido derrotado en el 2000 tuvo un retorno triunfante. Evidenciando la vitalidad del régimen posrevolucionario, no obstante, la alternancia partidista.

A pesar de los loables esfuerzos procedimentales, México no ha logrado adelantos sustantivos en la transformación de la estructura de poder real. Los actores de viejo cuño persisten en sus maniobras para mantener sus áreas de influencia, para lo cual realizan una mutación ajustándose a la normatividad, promovida y avalada por ellos, para legitimar su actuar. Con una institucionalidad y legalidad votada desde los circuitos del poder, las élites justifican sus privilegios amparados en el discurso electoral $^{2}$. Si bien con la democracia representativa se modernizaron los engranes de acceso al poder, las prácticas y los presupuestos de las mismas se mantienen

\footnotetext{
${ }^{2}$ El conflicto de clase es una noción que el Estado mexicano ha sido muy cuidadoso de mantener alejado del imaginario de la sociedad mexicana. En ese sentido, se ha difundido la idea que las condiciones de vida son resultado de las bondades del gobierno, y más recientemente de los esfuerzos individuales. En consecuencia, para tener prosperidad en materia de igualdad y justicia social, la vía es el voto legitimando a los gobernantes. Lo paradójico del asunto, es que esos gobernantes son protagonistas ligados directa o indirectamente a las élites que por años han impuesto su hegemonía en el país. En suma, conforme ha transcurrido el tiempo de la democracia, más palpable es la insuficiencia de los ajustes solamente electorales, para hablar de un cambio político de fondo.
} 
inalterables. El conteo de votos y vigilancia de los comícios es impecable, pero el uso discrecional de las componendas es la parte turbia del proceso (MARTIN, 2013).

Así las cosas, dos certezas se presentan de manera inexcusable hoy día: a) el creciente desaliento hacia la promesa democrática, y 2) la insuficiencia de la narrativa en torno a los comicios para alentar una profunda transformación política y social. En este contexto, para la sucesión presidencial de 2018 las probabilidades del PRI repitiendo en la presidencia de la república, son por demás inciertas. Dado el clima político de insatisfacción ciudadana donde violencia, pobreza, corrupción e impunidad, son los componentes reiterados de la administración presidencial vigente.

La falta de correspondencia entre el prédica y los hechos concretos, aunado a los habituales dislates de los políticos, se traduce día a día en un desplome de credibilidad agotando la paciencia ciudadana hacia la política institucional. Los resultados del Latinobarómetro en su Informe 2017 así lo ratifican, al reportar como los mexicanos ocupan los últimos lugares en satisfacción con la democracia (LATINOBARÓMETRO, 2017). Un hastío político cruzando la participación ciudadana, en un contexto marcado por una tensión de pobreza e inseguridad pública.

Por ende, derechos sociales y libertades políticas no se podrán desplegar a su máxima expresión, sin equidad y paz social en la obtención de recursos materiales y culturales. En palabras de Seymour Lipset, un clásico de la investigación política, "[...] la democracia se relaciona con el estado de desarrollo económico. Cuanto más próspera sea una nación, tanto mayor son las posibilidades de que mantendrá una democracia” (LIPSET, 1993, p. 44).

Así entonces, ser ciudadano en el sentido amplio del vocablo, se vincula al recorrido civilizatorio en los modos de organización institucional permitiendo al individuo arribar a un pleno bienestar, construyendo una fluida articulación entre la esfera privada y pública en aras del bien general. En ese sentido, convencidos de que el florecimiento de la idoneidad ciudadana va más allá de las urnas. Indispensable es revisar las situaciones de pobreza, violencia, inseguridad y tecnologías de la información, vigentes en la realidad mexicana, valorando su eventual incidencia en una actividad civil virtuosa, con lo cual la articulación de una identidad ciudadana democrática tendrá más posibilidades de cristalizar.

\section{Inseguridad y violencia}

Desde mediados de la década pasada, episodios asociados con el delito son ubicados con prioridad en la agenda gubernamental. Una centralidad en torno al 
tema de la inseguridad pública, donde secuestros, ajusticiamientos, robos de autos, extorsiones, trata de personas, narcotráfico, entre otros, son incidentes recurrentes en varias entidades del país. Sucesos donde la constante es el excesivo grado de intimidación, desde la agresión verbal, el maltrato físico, la tortura hasta el asesinato sin miramiento alguno. Una faceta de la violencia que sistemáticamente ha sido asociada con la criminalidad, generando percepciones de miedo e incertidumbre entre los habitantes.

Este incremento de la violencia social se vincula con la guerra desplegada contra el narcotráfico desde el gobierno de Felipe Calderón. Esta lucha contra las drogas, tiene su soporte en la política prohibicionista impulsada en los años 70 por los Estados Unidos a través del gobierno de Richard Nixon. La confrontación al narcotráfico ha estado presente desde hace 40 años, pero es en este período cuando se decide militarizarla con los resultados ya vistos (CASTAŃEDA, 2016). En el cumplimiento de esa empresa, las fuerzas armadas pasaron abruptamente de los cuarteles a las calles. Una presencia militar que puso en entredicho la capacidad de instituciones y autoridades civiles ante esa problemática. El efecto colateral resultó devastador, condujo al país a una irrefrenable espiral de violencia dejando un costoso saldo de desaparecidos, desplazados, torturados y miles de muertos. Aunado a la percepción de impotencia estatal para afrontar con suficiencia el ascenso de los carteles de la droga (PEREYRA, 2012; GUERRERO, 2011).

Sin conocerse un registro oficial de esta oleada de víctimas, a finales de 2016, según una estadística del Diario Reforma (31-12-2016) denominada Ejecutómetro, se había llegado a más de 80 mil muertos, producto de este flujo de violencia iniciada en 2006. Y solo en el sexenio actual, rebasaba los 38 mil. Revisando el gráfico 1, destaca el vertiginoso aumento de homicidios dolosos entre 2007 y 2011, simultáneo con el recrudecimiento de la batalla contra las cúpulas del narcotráfico. Ello sin considerar la progresiva actividad delictiva en otras áreas, algunas íntimamente relacionadas a la búsqueda de fuentes alternas de ingresos por parte de los cárteles. $\mathrm{O}$ bien, como resultado de su anulación, motivando el surgimiento de numerosas células criminales, quienes sin contemplaciones disputan mantener o apoderarse de nuevos enclaves (ESCALANTE, 2011; GUERRERO, 2016). 
Gráfico 1 - Ejecuciones en México 2006-2017

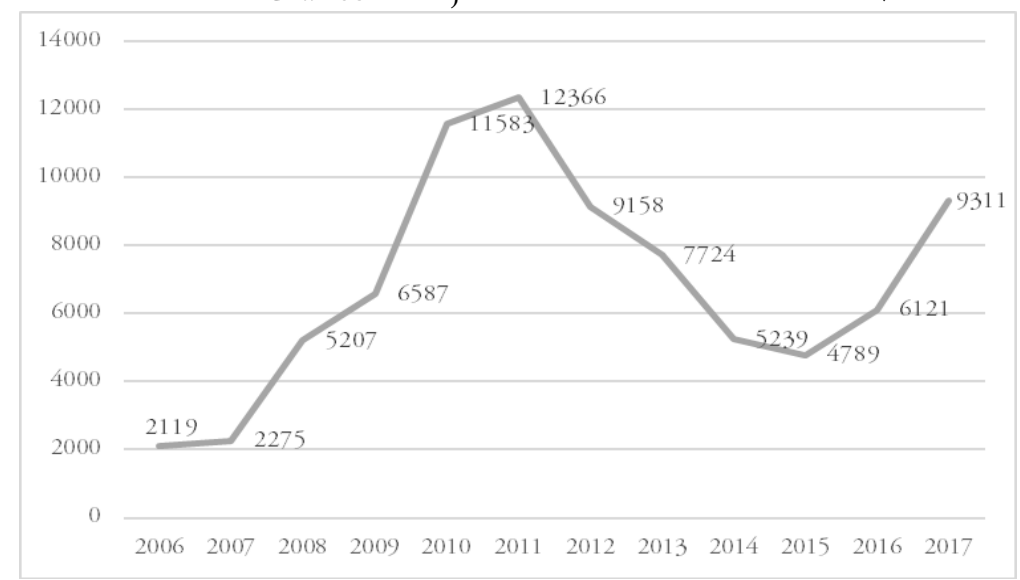

Fuente: Reforma, 2016-2017.

A partir de 2012 se aprecia una caída en las ejecuciones, aunque todavía distante de las cifras registradas en 2006. Los datos dan cuenta de una nación atrapada entre la inseguridad y la violencia. Esta última, estrechamente vinculada a la lucha contra las drogas; mientras la primera, sin estar plenamente unida al narcotráfico, desdobla otras facetas del crimen, con un ascenso indispensable de ser considerado (CIDAC, 2015). La evolución de prevalencia delictiva que registra el Instituto Nacional de Estadística y Geografía (INEGI) entre 2010 y 2015, indica una tasa porcentual en aumento hasta 2013, conservando ese grado en 2015, a la par de un reflujo en ese mismo período en varias entidades. Aunque habría algunas como Baja California Norte, El Distrito Federal, Estado de México, en el citado lapso, que han mantenido sus dígitos por arriba de la media nacional (INEGI-ENVIPE, 2017).

$\mathrm{Al}$ año 2016, además de los estados ya señalados, destacan Baja California Sur, Guanajuato, Jalisco, Morelos y Quintana Roo, con una pauta de delitos por encima del promedio. A pesar de los altibajos en los números, con algunas regiones subiendo en la clasificación y otros bajando, o viceversa, el trazo es de una sociedad cada vez más desgarrada en su tejido social. Con un Estado deteriorado por los intereses corporativos, aprisionado en una renovación institucional iniciada a mediados de los años noventa, pero aún inconclusa sin lograr llegar a la meta prometida (ZAPATA, 2004; BIZBERG, 2010).

Respecto al sujeto de la criminalidad, cabe señalar el desacato de las reglas no es innato de las capas depauperadas, también es usual entre los estratos medios y altos. Empero, los más publicitados, estigmatizados y castigados por la 
institucionalidad jurídico-social son los cometidos por los sospechosos comunes (PÉREZ, 2013). Por ende, con bastante reserva es de admitir las afirmaciones: "la delincuencia está desatada", "no hay quien controle a la delincuencia", "los delincuentes están en todas partes", "hay que acabar con la delincuencia a como dé lugar”, en tanto son planteamientos genéricos cuyo punto de partida es un equivocado principio de uniformidad de los infractores.

Con mesura habrá de ser examinado el protocolo de la violencia. Ésta ha dejado de ser indivisible, mostrándose como un paradigma heterogéneo, debiendo hablarse ya no de la violencia sino de las violencias; violencia urbana, violencia familiar, violencia policiaca, violencia simbólica, violencia verbal, violencia étnica, contra las mujeres, y en general, cualquier conglomerado social que alberga en su seno todo este caudal de prácticas agresivas.

La diferencia entre las civilizaciones para exteriorizarlas con mayor o menor intensidad, reside en los grados de institucionalización alcanzados por sus asociaciones políticas. Esto es, en los arreglos de convivencia, reconocimiento y representación incluyentes de la mayoría de la comunidad, condensándose los mismos en aceptadas reglas de organización y desarrollo social. Cuando estos acuerdos de integración social se rompen o son obsoletos, quedan evidenciados a través de conductas indisciplinadas, con el ulterior desborde de los cánones de vida convencionales (GONZALEZ, 2006).

Recuperando este planteamiento en nuestro entorno, puede apreciarse una acusada crisis institucional en sus distintos niveles de asociación. Secuela de la convergencia de dos abrumadores procesos que están motivando desconcierto especialmente entre los jóvenes: a) por un lado, se está ante la presencia de una crisis de las prácticas corporativas tradicionales, consecuencia del quiebre normativo sobre el cual se había edificado su modus vivendi por más de setenta años; b) y el cada vez más acelerado proceso de exclusión a que están siendo sometidos los jóvenes por la lógica del mercado, suscitando en ellos el convencimiento del no future. Con una ausencia de porvenir, deterioro en la conciencia solidaria y un creciente escepticismo en política (BANCO MUNDIAL, 2012).

Por años el hacer social y político estuvo profusamente nutrido de creencias y rutinas autoritarias, sin ser prioridad la construcción de mediaciones institucionales ciudadanas en cada una de las ínsulas del corpus social. Pero ahora cuando es notable el desgaste del viejo régimen, el trasiego a otros modos de congregación política está resultando sumamente oneroso. Ante la parvedad de instancias democráticas, 
legítimas y funcionales garantes de este proceso, los vacíos de poder son ocupados y lucrados impunemente por policías y militares. Quienes tienen o tuvieron en algún momento contacto ex profeso con la violencia institucionalizada. La criminalidad tiene en estos especialistas del uso de la fuerza, a sus principales gestores materiales o intelectuales (INSTITUTO MEXICANO DE ESTUDIOS DE LA CRIMINALIDAD ORGANIZADA, A.C , 1998).

Es posible constatar esto último, con solo revisar sucintamente la información diaria en los diferentes medios de comunicación, y hallaremos que los actores principales en materia de robos, secuestros y homicidios realizados con violencia, son jóvenes con un marcado origen social marginal y policías o ex-policías. Unos y otros, concentran la infinidad de asaltos a casas-habitación, transeúntes, taxis, microbuses, robos de autos, secuestros momentáneos (los llamados exprés) o de larga data, pero en estos incidentes la constante es el sobrado grado de violencia utilizado. Por lo tanto, tenemos dos agrupamientos en apariencia opuestos, pero que sin embargo actúan de manera similar. ¿Ello a qué se debe? ¿es reflejo de una forma de vida estructural en crisis en el que abuso e impunidad lejos de ser anormales, han cumplido un rol determinante en los procesos de reproducción social y política?

La respuesta es afirmativa en regímenes autoritarios como el mexicano, donde la premisa central es mantener el "orden político" (REYNA, 1979). Entendido el mismo como razón de estado, justificando recurrir a los medios necesarios para cumplir tal objetivo, aunque estos sean contrarios a los intereses y garantías de la colectividad. La policía en sistemas autoritarios es una institución que procesa su actuar por encima de la legalidad instituida, su naturaleza organizativa y de acción está signada por la lealtad al jefe, al superior, al líder; en suma, a quien tiene el poder. En tiempo reciente el país sufre una crisis de derechos humanos, teniendo en el caso Ayotzinapa su referente más emblemático, siendo solo la punta del iceberg. Situación que ha colocado a México en el centro del debate con los respectivos organismos internacionales encargados de esta temática (LA JORNADA, 2018).

De lo expresado líneas arriba tres hipótesis igual de inquietantes trascienden: la primera llevaría a confirmar una peligrosa descomposición entre los segmentos marginados de los elementales patrones sociales de cohesión, derivando ello en un manifiesto resentimiento social, cuyo desahogo es canalizado mediante este tipo de conductas. Otra, asistimos a un desfallecimiento de la forma de estado corporativa posrevolucionaria, siendo aprovechada de manera oportunista por asociaciones clandestinas como la mafia o el narcotráfico. En ese sentido, la violencia desatada en las calles estaría dirigida a exhibir la vacilación estatal en el control de este recurso. 
Finalmente, la tercera presunción identificaría el uso de la violencia como parte de una estrategia de los sectores conservadores del "ancien regime", conducente a generar un clima de terror neutralizando la incorporación de los individuos al debate político.

La violencia que alimenta una situación de terror se distingue de la violencia que sostiene la eficacia continuadora de un poder coercitivo porque ésta es mesurada y previsible, en tanto que la otra es desmesurada e imprevisible...En el caso del terror la violencia ataca en forma causal comportamientos no profesados y en los que se manifiesta, o se pretende que se manifieste, aún en el modo más indirecto y más incierto una crítica o una oposición; además la violencia ataca estos comportamientos no en una forma discriminada y ponderada sino ciegamente, como una furia salvaje; aún el pretexto más leve puede causar la muerte o la privación de la libertad personal. Este tipo de violencia genera en la población un miedo irracional, perennemente amenazador y sin límites precisos, que impide cualquier cálculo o previsión (BOBBIO, 1982, p. 1675).

Preocupados por sobrevivir económicamente, los ciudadanos además deben cuidarse de la agresión criminal en las calles. Un doble desasosiego que apenas les deja aliento y convicción para actuar políticamente. Porque ciertamente es de reconocer el interés de participar ¿pero, mediante qué medios o instancias?, no hay muchas alternativas dado el bajo margen de credibilidad de los mexicanos en sus instituciones y organizaciones políticas.

Sin duda, el país está inserto en un delicado tiempo histórico, con una acentuada desazón respecto a los acontecimientos venideros. Hay frustración e indignación contra los directivos de la seguridad pública, quienes por su parte la tratan de atemperar impulsando nuevos reglamentos jurídicos, mandando más policías a las calles, o aumentando la compra de armamento altamente sofisticado. Sin embargo, la rehabilitación de la seguridad pública no se hará eficiente con la simple aplicación de criterios administrativos y jurídicos.

Es imperioso avanzar reconociendo que se trata de un profundo conflicto social y estructural, distante en su resolución de la aplicación simple de medidas técnicas. Y desde ahí esclarecer en sus justos términos la lógica del trinomio delincuencia-violencia-seguridad pública. Caso contrario, como hasta hoy ha sucedido, se seguirá polemizando difusamente acerca de la inmoralidad policiaca o de 
la deshumanización de los delincuentes, pero sin lograr aclarar en su cabal esencia, la causalidad y alcances de tal contingencia.

\section{Pobreza y desigualdad}

La segunda línea de reflexión, está íntimamente relacionada a lo arriba descrito, y que también es evidencia de un endeble crecimiento económico y frágil desarrollo social en los recientes 40 ańos. Fruto del modelo de libre mercado y la apertura de fronteras al intercambio comercial. En ese marco globalizador, la pobreza se asentó como un mal endémico, y para mitigarla se confeccionó desde finales de los años 80 una incipiente política social gestionada a través de la Secretaria de Desarrollo Social (SEDESOL). Pero dadas las magnitudes del problema, rápidamente se posiciono en un lugar relevante dentro de la agenda social y política. Empujando al gobierno a la promulgación en 2004 de la Ley de Desarrollo Social, donde se establecen los principios guía de la política social, así como los derechos fundamentales que toda persona habrá de disfrutar.

En agosto de 2005 se crea el Consejo Nacional de Evaluación de la Política de Desarrollo Social (CONEVAL), como organismo público descentralizado:

Con las funciones de normar y coordinar la evaluación de la política nacional de desarrollo social y las políticas, programas y acciones, que ejecuten las dependencias públicas, y establecer los lineamientos y criterios para la definición, identificación y medición de pobreza, garantizando la transparencia, objetividad y rigor técnico en dicha actividad (CONEVAL, 2016, p. 8).

Durante la reciente década, esta institución se ha encargado de dar seguimiento y evaluar los diversos programas sociales dirigidos a atacar la pobreza, a la par de realizar metódicamente su medición. Un ejercicio no exento de polémica ya que convencionalmente se le ha pensado asociada habitualmente al ingreso. Sin embargo, a raíz de múltiples estudios y valoraciones el gobierno asume la categoría multidimensional de la misma, donde la retribución es sólo una de las variables a examinar en este cálculo. Las otras se vinculan con los derechos sociales, es decir, se "reconoce que la población pobre padece insuficiencia de recursos económicos y, al mismo tiempo, se ve vulnerada en el ejercicio de sus derechos fundamentales debido a la falta de acceso a la alimentación, la salud, la educación, la seguridad social o a una vivienda digna" (CONEVAL, 2014, p. 1). 
Con este presupuesto orientando el escrutinio de la pobreza, según el reciente informe de CONEVAL: Evaluación de la Política de Desarrollo Social en México 2016, nos indica que poco menos la mitad de los residentes en México vivía en pobreza y/o extrema pobreza. Esto es, que de 2010 a 2016 la pobreza disminuyó en términos relativos, pasando del 46,1\% al 43,6\%. Aunque en absolutos se incrementó en poco más de medio millón, transitando de 52,8 millones a 53,4 millones. De los cuales, en $2016,7,6 \%$ se encontraban en extrema pobreza y $35,9 \%$ en pobreza moderada. Con este enfoque la pobreza se entreteje con la dimensión de la desigualdad social, en tanto algún bien como educación, salud, alimentación o vivienda, es sumamente disímil en su repartición.

Tabla 1 - Medición de la pobreza 2016

\begin{tabular}{|c|c|c|c|c|c|c|c|c|c|c|c|c|c|c|c|}
\hline \multicolumn{16}{|c|}{ Porcentaje, número de personas y carencias promedio por indicador de pobreza, 2008-2016 } \\
\hline \multirow{3}{*}{ Indicadores } & \multicolumn{15}{|c|}{ Estados Unidos Mexicanos } \\
\hline & \multicolumn{5}{|c|}{ Porcentaje } & \multicolumn{5}{|c|}{ Millones de personas } & \multicolumn{5}{|c|}{ Carencias promedio (por indicador) } \\
\hline & 2008 & 2010 & 2012 & 2014 & 2016 & 2008 & 2010 & 2012 & 2014 & 2016 & 2008 & 2010 & 2012 & 2014 & 2016 \\
\hline \multicolumn{16}{|l|}{ Pobreza } \\
\hline Población en situación de pobreza & 44,4 & 46,1 & 45,5 & 46,2 & 43,6 & 49,5 & 52,8 & 53,3 & 55,3 & 53,4 & 2.8 & 2.6 & 2.4 & 2.3 & 2.2 \\
\hline $\begin{array}{l}\text { Población en situación de pobreza } \\
\text { moderada }\end{array}$ & 33,3 & 34,8 & 35,7 & 36,6 & 35,9 & 37,2 & 39,8 & 41,8 & 43,9 & 44,0 & 2.4 & 2.2 & 2.0 & 1.9 & 1.9 \\
\hline $\begin{array}{l}\text { Población en situaciòn de pobreza } \\
\text { extrema }\end{array}$ & 11,0 & 11,3 & 9,8 & 9,5 & 7,6 & 12,3 & 13,0 & 11,5 & 11,4 & 9,4 & 3.9 & 3.8 & 3.7 & 3.6 & 3.5 \\
\hline $\begin{array}{l}\text { Población vulnerable por carencias } \\
\text { sociales }\end{array}$ & 32,3 & 28,1 & 28,6 & 26,3 & 26,8 & 36,0 & 32,1 & 33,5 & 31,5 & 32,9 & 2.0 & 1.9 & 1.8 & 1.8 & 1.7 \\
\hline Población vulnerable por ingresos & 4,7 & 5,9 & 6,2 & 7,1 & 7,0 & 5,2 & 6,7 & 7,2 & 8,5 & 8,6 & 0.0 & 0.0 & 0.0 & 0.0 & 0.0 \\
\hline Población no pobre y no vulnerable & 18,7 & 19,9 & 19,8 & 20,5 & 22,6 & 20,9 & 22,8 & 23,2 & 24,6 & 27,8 & 0.0 & 0.0 & 0.0 & 0.0 & 0.0 \\
\hline \multicolumn{16}{|l|}{ Privaciòn social } \\
\hline $\begin{array}{l}\text { Población con al menos una carencia } \\
\text { social }\end{array}$ & 76,6 & 74,2 & 74,1 & 72,4 & 70,4 & 85,5 & 85,0 & 86,9 & 86,8 & 86,3 & 2.4 & 2.3 & 2.2 & 2.1 & 2.0 \\
\hline $\begin{array}{l}\text { Población con al menos tres carencias } \\
\text { sociales }\end{array}$ & 31,7 & 28,2 & 23,9 & 22,1 & 18,7 & 35,4 & 32,4 & 28,1 & 26,5 & 23,0 & 3.7 & 3.6 & 3.5 & 3.5 & 3.4 \\
\hline \multicolumn{16}{|l|}{ Indicadores de carencia social } \\
\hline Rezago educativo & 21,9 & 20,7 & 19,2 & 18,7 & 17,4 & 24,5 & 23,7 & 22,6 & 22,4 & 21,3 & 3.2 & 3.1 & 2.9 & 2.8 & 2.6 \\
\hline $\begin{array}{l}\text { Carencia por acceso a los servicios de } \\
\text { salud }\end{array}$ & 38,4 & 29,2 & 21,5 & 18,2 & 15,5 & 42,8 & 33,5 & 25,3 & 21,8 & 19,1 & 3.0 & 3.0 & 2.8 & 2.8 & 2.7 \\
\hline Carencia por acceso a la seguridad social & 65,0 & 60,7 & 61,2 & 58,5 & 55,8 & 72,5 & 69,6 & 71,8 & 70,1 & 68,4 & 2.6 & 2.5 & 2.3 & 2.3 & 2.2 \\
\hline $\begin{array}{l}\text { Carencia por calidad y espacios de la } \\
\text { vivienda }\end{array}$ & 17,7 & 15,2 & 13,6 & 12,3 & 12,0 & 19,7 & 17,4 & 15,9 & 14,8 & 14,8 & 3.7 & 3.6 & 3.4 & 3.3 & 3.1 \\
\hline $\begin{array}{l}\text { Carencia por acceso a los servicios } \\
\text { básicos en la vivienda }\end{array}$ & 22,9 & 22,9 & 21,2 & 21,2 & 19,3 & 25,5 & 26,3 & 24,9 & 25,4 & 23,7 & 3.6 & 3.3 & 3.2 & 3.1 & 2.9 \\
\hline Carencia por acceso a la alimentación & 21,7 & 24,8 & 23,3 & 23,4 & 20,1 & 24,3 & 28,4 & 27,4 & 28,0 & 24,6 & 3.3 & 3.0 & 2.9 & 2.8 & 2.6 \\
\hline \multicolumn{16}{|l|}{ Bienestar } \\
\hline $\begin{array}{l}\text { Poblaciòn con ingreso inferior a la línea } \\
\text { de bienestar mínimo }\end{array}$ & 16,8 & 19,4 & 20,0 & 20,6 & 17,5 & 18,7 & 22,2 & 23,5 & 24,6 & 21,4 & 3.1 & 2.9 & 2.5 & 2.5 & 2.4 \\
\hline $\begin{array}{l}\text { Poblaciòn por acceso inferior a la línea } \\
\text { de bienestar }\end{array}$ & 49,0 & 52,0 & 51,6 & 53,2 & 50,6 & 54,7 & 59,6 & 60,6 & 63,8 & 62,0 & 2.5 & 2.3 & 2.1 & 2.0 & 1.9 \\
\hline
\end{tabular}

Fuente: CONEVAL, 2016.

Estos rasgos generales de la pobreza se desglosan en una detallada clasificación en varios niveles, posibles de distinguir con suma claridad en la Tabla 1 del citado informe de 2016. Multiplicidad de gradaciones con segmentos vulnerables, en carencia social o viviendo por debajo de la línea de bienestar. Una matriz de análisis 
de la pobreza, valiosa por la generosa información proporcionada, pero que su examen a fondo sobrepasa los objetivos del actual escrito. Sin embargo, es apropiado revisarla porque nos alecciona del lugar ocupado por los mexicanos en materia de aproximación a los recursos, y por ende de las condiciones de equidad social.

De igual forma, una lectura de la evolución de la pobreza en lo general, y por entidades en lo particular, es posible llevarla a cabo con más detalle en el sitio oficial del CONEVAL ${ }^{3}$. Este acercamiento nos muestra una nación quebrantada, con los mayores rezagos sociales concentrados en la región sur. Destacando entidades como Campeche, Chiapas, Guerrero, Hidalgo, Michoacán, Oaxaca, Puebla, SLP, Tabasco, Tlaxcala, donde su indicador de pobreza se estaciona por arriba de la media. Los demás estados se mantienen dentro de magnitudes estables. Aunque es perceptible una orientación ascendente, incluso en aquellas áreas con bajas marcas. Estos guarismos brindan una dura imagen de lo distante en su erradicación, siendo una deuda pendiente que limita el desarrollo incluyente de la sociedad.

Asimismo, las privaciones sociales observadas en la Tabla 1, nos permiten colegir la escasa participación en los recursos sociales por parte de los sectores desamparados. Perjudicando su calidad de vida, obra de dispositivos institucionales excluyentes, complementados por representaciones culturales racistas y discriminatorias que por generaciones han prevalecido en el imaginario social. Siendo aquellos compuestos por indígenas, mujeres, viejos, niños, migrantes, los más expuestos a una desventajosa justicia distributiva.

Esta menguada condición de bienestar para buena parte de la colectividad, queda bosquejada a través de bajos salarios, desempleo, salud mermada y una deteriorada escolaridad. La entrada a mejores condiciones de vida es constreñida ensanchando la distinción social. Mientras del otro lado de la moneda se registra una desproporcionada concentración de la riqueza en manos de unos cuantos. Al respecto por demás revelador de este fenómeno es el estudio de OXFAM, México (ESQUIVEL, 2016), exhibiendo los privilegios de las minorías en medio de un océano de pobreza y miserias.

Dicha centralización profundiza la brecha de bienestar entre los individuos y/o clases. Según cifras de INEGI, el 10\% de la población acapara el 36\% de la riqueza, mientras el $90 \%$ se distribuye el $74 \%$ restante. O como bien se expone en el gráfico 2, los últimos cuatro deciles (VII, VIII, IX y X) monopolizan el 72\% del total

${ }^{3}$ Disponível em: <https://www.coneval.org.mx/Medicion/Paginas/PobrezaInicio.aspx>. Acesso em 02 fev. 2018. 
de ingresos. Igualmente, y según los datos arrojados por la Encuesta Nacional de Ingresos y Gastos de los Hogares 2016 (ENIGH), los hogares del primer decil tuvieron un ingreso promedio trimestral de 8,166 pesos, que les representó 90,7 al día. En tanto para los del décimo decil, fue de 168,855 pesos al trimestre, que implicó 1,876 al día. En síntesis, una estampa por demás ostensible del contraste social y la precariedad en el México contemporáneo.

Gráfico 2 - Ingresos por deciles ENIGH 2016 (\%)

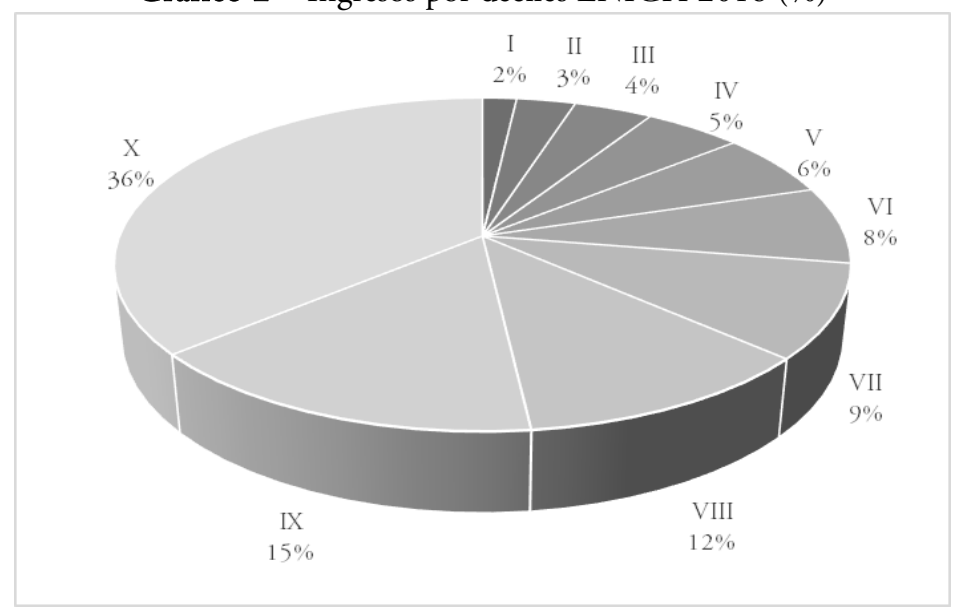

Fuente: Encuesta Nacional de Ingresos y Gastos de los Hogares (ENIGH-INEGI 2016).

Con este panorama de trasfondo, las nuevas generaciones resienten su desapego de los réditos del progreso tan reiteradamente encumbrados. En su lugar, un nebuloso horizonte fomenta el desgarramiento interno en los principios de adaptación y motivación de los jóvenes. Asimismo, el incremento de asentamientos marginales, es cada vez más visible en las ciudades. Una derivación de la falta de recompensas en el campo, concitando a los lugareńos a migrar hacia las periferias metropolitanas (o bien a los Estados Unidos de Norteamérica), en la búsqueda de lograr una subsistencia básica. Aunque llegar al espacio urbano constituya, - no como antaño una búsqueda de ascenso social -, simplemente subsistir. Predisponiendo la conformación de nuevas capas sociales por debajo de los pobres ya existentes.

Colonos asentados en suburbios muy distantes de los barrios obreros pobres, donde no solamente requieren de los servicios indispensables como agua, electricidad, drenaje, y otros servicios, sino algo peor, sus viviendas están construidas en demarcaciones de alto riesgo como barrancas, cerros, o en cercanía de los ríos. Esta 
urbanización salvaje resultado de una dilatada permisividad corporativa, ha hecho crecer las ciudades, pero a contrapelo de un decremento en el rango de vida ofrecida por las mismas. La tendencia es hacia una manifestación de la pobreza en otra dimensión; se puede tener agua, salud, instrucción, vivienda, pero con amplias dudas respecto a su calidad.

Con un déficit cada vez mayor de los bienes públicos, ligado al persistente desmantelamiento de la infraestructura de bienestar social. Surge una nueva connotación tanto en los parámetros de congregación de los individuos, como de sus potenciales solidaridades. Exclusión social conduciendo a una ostensible organización-desorganización de los mundos simbólicos, colectivos e individuales. Reproduciendo una muchedumbre cada vez más numerosa de hombres y mujeres, alejados de la normatividad institucional, limitando su acceso a los provechos de la integración. Padecen una cancelación de oportunidades vitales al entrar en la directriz de la fragmentación y la expulsión social. Marginación estructural con repercusiones en la vivencia diaria, convirtiéndolos en receptores de agravios frecuentes, resistiendo al límite, asolados por la hostilidad y el abuso. La distinción entre el "nosotros" y los "otros", que en buena medida se sustenta en acciones de violencia y humillación, es eficaz al mantener la dominación de un grupo (ELIAS y SCOTSON, 2016).

\section{Acceso a la información: Internet y redes sociales}

Las Tecnologías de la Información y las Comunicaciones (TICs), son el corazón de la producción social y económica en nuestro tiempo. Sin embargo, es importante enfatizar la productividad y competitividad no se afinca en el rendimiento de las TICs, sino en la creatividad de las personas innovando en los usos de estos accesorios. Evitando caer en la ingenuidad de considerar la información por sí misma procrea conocimientos. Esto no es correcto, las TIC's hay que ubicarlas tan solo como el gran pivote modernizador de formas, y ejercicios novedosos de reflexión, clasificación y argumentación.

Poseer conocimiento, sea en la esfera que sea, es capaz de realizar actividades intelectuales o manuales. El conocimiento es por tanto fundamentalmente una capacidad cognoscitiva. La información, en cambio, es un conjunto de datos, estructurados y formateados pero inertes e inactivos hasta que no sean utilizados por los que tienen el conocimiento suficiente para interpretarlos y manipularlos (DAVID y FORAY, 2012, p. 12). 
De suyo, este tránsito no es en sí mismo cuestionable, el desasosiego no radica en este abundante despliegue de modernas tecnologías, y en su impacto en los consecuentes ejes del pensamiento, sino en los alcances directos a las formas de organización y acuerdo social. En un contexto global tan desigual e inequitativo, cuántas regiones del mundo se encuentran lo suficientemente facultadas en la recepción de la revolución digital e incorporarla a los diversificados circuitos de la vida social. Obligándolas entre otras cosas, a educar una fuerza de trabajo competitiva a escala mundial y a su constante actualización en materia de procedimientos digitales.

Este comprometido entorno, precisa interrogarse acerca de la viabilidad de acogida a estos novedosos métodos por parte de la totalidad de las congregaciones sociales en cada país; o bien, si entre naciones cooperan a la reducción de los desniveles existentes. La bonanza social y económica del siglo XXI se condensa en la apropiación y creación de información, con lo cual el conflicto social se desplaza de las esferas de la trasformación material, al universo de la creación simbólica. Amplia gama de lugares donde la brecha digital se levanta como factor de desequilibrios internos y externos. Un escenario asociado indubitablemente al uso de las TICs que, según sus capacidades de infraestructura en telecomunicaciones e informática, le posibilitará a cada pueblo sumarse de manera vigorosa y estable a la sociedad red (CASTELLS, 1999).

Adherencia donde el saber leer y escribir convencional, es insuficiente al afrontar esta vertiginosa metamorfosis tecnológica. Requiriéndose una segunda alfabetización con desconocidas formas de comunicarse y aprehender el hábitat. Así como de un acceso garantizado al internet, con una pericia de manejo por encima de la media, teniendo claro el perfil de los servicios ofertados en la World Wide Web (www). Lograr estas competencias es nodal para fijar las bases de una posible ciudadanía digital.

La reinante economía demanda no solamente la técnica como tal, necesita de inversiones en recursos humanos altamente calificados. Además, reivindica el impulso de una industria garante de los insumos de reciente cuńo, exigidos en las redes de fabricación o investigación en los disímiles perímetros del saber. En otros términos, este paso hacia la llamada vida digital, emplaza una socialización y/o capacitación de este lenguaje, incorporando trabajadores, empresarios, consumidores, políticos, investigadores. Aparte de crear una sensibilidad en los gobernantes acerca de la gestión y promoción de ciencias aplicadas. 
Frente a una abrumadora vocación globalizadora cubriendo el orbe, el planteamiento es ¿cómo se presenta la incorporación a la WEB (usuarios de internet) en el caso de México? Para ello ilustrativos son los datos proporcionados por la Encuesta Nacional sobre Disponibilidad de Tecnologías de la Información en Hogares (ENDUTIH) 2017, aplicada por INEGI y resumidos en la Tabla 2 y en la Tabla 3. En la Tabla 2, podemos observar un valioso aumento en la cobertura del servicio de internet, con un $50,9 \%$ en los hogares y un $63,9 \%$ en los usuarios individuales. Igualmente, lo que ya es por demás conocido, las nuevas generaciones son las más asiduas consumidoras. Mientras en su uso, predomina la búsqueda de información, diversión y el comunicarse. Quedando en los últimos lugares disponer de ellas para trámites de servicios o transacciones bancarias comerciales (Tabla 3).

Tabla 2 - Uso de las tecnologías de la información 2017

\section{Numeralia}

Resultados de la encuesta nacional sobre disponibilidad y uso de tecnologías de la información en los hogares, 2017

\begin{tabular}{c|c|c}
\hline $\begin{array}{c}\text { Proporción de hogares con } \\
\text { computadora }\end{array}$ & $\begin{array}{c}\text { Proporción de hogares con } \\
\text { Internet }\end{array}$ & $\begin{array}{c}\text { Proporción de hogares con } \\
\text { televisor digital }\end{array}$ \\
\hline 0,454 & 0,509 & 0,705 \\
\hline $\begin{array}{c}\text { Proporción de usuarios de } \\
\text { computadora }\end{array}$ & $\begin{array}{c}\text { Proporción de usuarios de } \\
\text { Internet }\end{array}$ & $\begin{array}{c}\text { Proporción de usuarios de } \\
\text { telefonía celular }\end{array}$ \\
\hline 0,453 & 0,639 & 0,722 \\
\hline $\begin{array}{c}\text { Proporción de usuarios de } \\
\text { TIC por género }\end{array}$ & Mujeres & Hombres \\
\hline Computadora & 0,495 & 0,505 \\
\hline Internet & 0,508 & 0,492 \\
\hline Celular & 0,509 & 0,491 \\
\hline Usuarios de Internet por \\
género y edad
\end{tabular}

Fuente: Encuesta Nacional sobre Disponibilidad y Uso de las Tecnologías de la Información

(ENDUTIH-Inegi 2017). 
Tabla 3 - Usuarios de Internet por tipo de uso

\begin{tabular}{c|c}
\hline Actividad & Proporciòn \\
\hline Para obtener información & $96,9 \%$ \\
\hline Para entretenimiento & $91,4 \%$ \\
\hline Para comunicarse & $90,0 \%$ \\
\hline Para acceder a contenidos audivisuales & $78,1 \%$ \\
\hline Para acceder a redes sociales & $76,6 \%$ \\
\hline Leer periòdicos, revistas o libros & $48,4 \%$ \\
\hline Para interactuar con el gobierno & $28,0 \%$ \\
\hline Para ordenar o comprar productos & $16,6 \%$ \\
\hline Para operaciones bancarias en línea & $12,9 \%$ \\
\hline
\end{tabular}

Fuente: Encuesta Nacional sobre Disponibilidad y Uso de las Tecnologías de la Información (ENDUTIH-Inegi 2017).

Examinando la cantidad de hogares con internet al año 2017, a modo de ponderar la disposición particular y uso que en lo rutinario se le puede dar a esta prestación, lo expuesto en la Tabla 2 es una tasa promedio de menos del 50\%. Que nos lleva a pensar en la perspectiva del vaso medio lleno o medio vacío, ya que, desde esta última, más de la mitad de las viviendas no tienen enlace a la www quedando al margen de sus potenciales beneficios. Y examinado en lo particular, esta ausencia se manifiesta con más pesadez en las franjas de pobreza expuestas en los estados de Chiapas, Guanajuato, Guerrero, Hidalgo, Michoacán, Oaxaca, Puebla, Tlaxcala, Veracruz y Zacatecas, situados por debajo de la media nacional. También es de resaltar son entidades con un considerable perfil rural, que las hace estar a la zaga de lo acontecido en los espacios urbanos en materia de su acceso a internet, como lo podemos constatar en el siguiente gráfico. Para estas regiones la dificultad de vivir en la sociedad de la información es doble, por un lado, estar asentados en comarcas con un fuerte déficit en materia de servicios de todo tipo, y por otro formar parte de territorios con una herencia de pobreza ancestral. 
Gráfico 3 - Usuarios de internet por entidad 2017

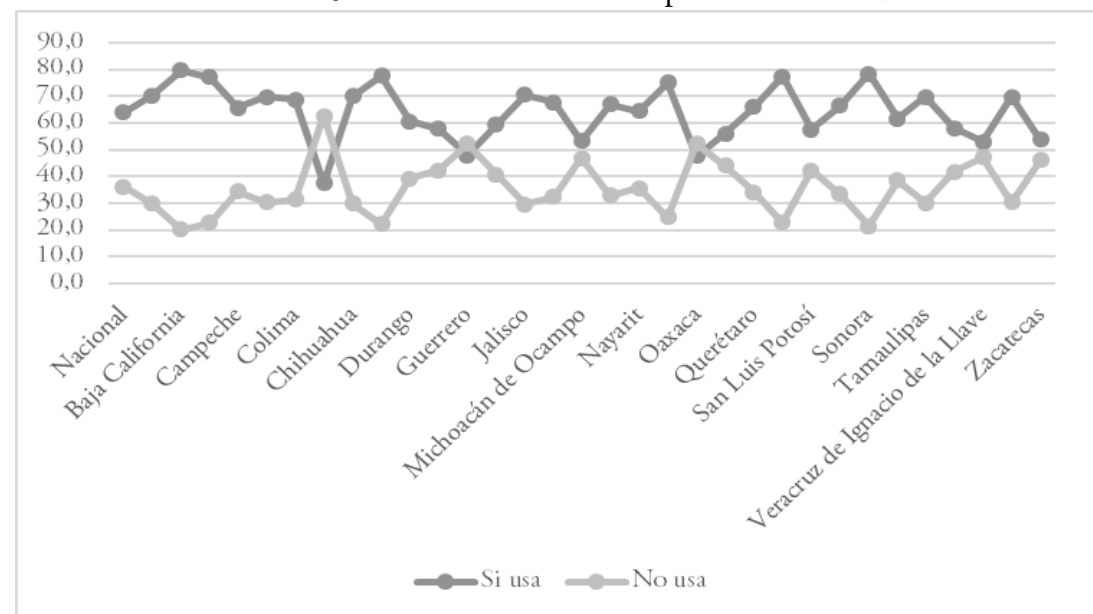

Fuente: Encuesta Nacional sobre Disponibilidad y Uso de las Tecnologías de la Información (ENDUTIH-Inegi 2017).

Desde las elecciones del año 2000 había quedado en evidencia la importancia de los mass media en los procesos electorales. En buena medida el triunfo de Vicente Fox se sustentó en el artificio de una imagen pública de líder carismático, capaz de dirigir al país hacia derroteros alternos a los logrados por el PRI. El tiempo indicó lo contrario, y es de reconocer el acertado manejo de su comunicación política, vendiendo un producto solicitado en esa coyuntura. El ańo 2006 no fue la excepción con el PAN reeligiéndose, centrado en una campaña apuntalada en discursos de miedo y odio. Lo relevante en todo esto es el papel sustantivo del quehacer mercadológico en derredor de cada candidato. Induciendo la disputa no en los programas políticos, sino en quién logra actos de mayor frivolidad y escarnio hacia su contrincante. Un uso pernicioso del espectáculo, dirigido a manipular las preferencias de la opinión pública al emitir su voto. Si bien una vez concluido este proceso, el elector quede nuevamente en el olvido, hasta la realización de nuevos comicios.

La televisión, la radio, los periódicos, como medios difusores de spots, carteles, encuestas, entrevistas, son piezas esenciales en el ascenso o demolición de políticos. La política como entretenimiento está ya definitivamente instalada en la vida pública moderna. $\mathrm{Y}$ en ese tenor, recientemente las redes sociales han irrumpido con un dinamismo digno de ser tomado en cuenta. Sea en las elecciones o en el día a día, la información que por las vías convencionales no saldría a luz pública, con el uso de internet es posible sea conocida. A través de este mecanismo, actores segregados o sin opciones de organización, están encontrando una alternativa de participación. Por 
naturaleza propia, la red abre la puerta en la democratización de significaciones e información. Y aquí se enfatiza en el internet, ya que, sin acceso, las redes sociales no tendrían su vía de expansión. Es el quid de la comunicación a futuro, por ello los intentos de su regulación puestos sobre la mesa en diferentes instancias.

Mientras desde el espectro demográfico, los jóvenes son los más activos usuarios de redes sociales. Haber crecido en una atmósfera cada vez más cibernética, los hace permeables a las innovaciones en ese terreno. Sin embargo, esa afinidad no garantiza por sí misma un adelanto político. Se necesita de una considerable difusión de insumos culturales y valorativos. Donde internet cumpliría el papel de medio y no fin, es un aditamento trascendente en la edificación de una condición democrática y cosmopolita, pero no se agota en sí mismo. La múltiple información sin coordenadasguía, puede resultar caótica y confundir los usos de la misma. De ahí la intensa tarea tanto del estado como de la sociedad civil, en pos de ordenar de la mejor manera el uso de la red y sus respectivas herramientas.

\section{Consideraciones finales}

Los elementos brindados a lo largo del texto, sirven para atestiguar México cuenta con electores presentes, pero queda pendiente, que la modernidad y el cambio político, fabriquen significativas condiciones de participación política de la ciudadanía, quien parece estar ausente en el laberinto de la democracia. La liberalización política presionó la apertura de algunos contornos de intervención, pero mantiene como deuda una débil cultura política democrática entre la población.

Los valores de sumisión y apatía son apoyados y difundidos a través de instituciones conservadoras y poco democráticas como la iglesia, la familia o los medios de información. Promoviendo la fragmentación y el sentimiento de desconfianza, y con ello un sujeto social desmovilizado y fraccionado ante las imposiciones desde el poder. Los magros logros democráticos han quedado acotados al circuito electoral, donde si bien hay elecciones y se vota por ciertos candidatos, la posibilidad real de participar en las decisiones trascendentales no es posible por los esquemas de poder establecidos.

Por ello parece "normal" que se conciba la vida pública como algo ajeno, exclusivo solo a los poderes fácticos, quienes a su vez hacen uso inicuo de los criterios legales en su imposición hegemónica. De esta forma, la razón jurídica se ha constituido en una vigorosa fuente de dominación simbólica. El éxito de la misma, es posible constatarlo en cualquier ámbito de la vida cotidiana, donde bajo el amparo de 
los reglamentos se siguen perpetrando cualquier cantidad de abusos de autoridad. Excesos propiciados por una quebradiza armazón institucional post-autoritaria, incapaz de limitar o suprimir la corrupción y la impunidad.

En este ambiente, pierden fuerza las imágenes liberales de ciudadanía basadas en el ejercicio legal de ciertas prerrogativas. Con un espacio público inclusivo a todas las identidades colectivas, de tal modo que el ideal de la sociedad implique un propósito genérico construido deliberativamente, aquilatando al residente como un ente activo en la toma de decisiones sobre el rumbo político.

La tarea pendiente de esta inconclusa transición política, es el impulso a la formación de una subjetividad universal. Un propósito no realizable solo con buenas intenciones o por decreto, se requiere superar condiciones estructurales perniciosas. Como son la trilogía ya trazada de pobreza, inseguridad y acceso a la información. En otros términos, superar el miedo a perder el patrimonio o la vida, tener acceso al mínimo bienestar, así como a un irrumpir civilizatorio que va de la mano con los conocimientos adquiridos.

El reto nodal en este cambio de época, es consolidar infraestructura y cobertura en lo económico y social. Por tal motivo, hablar de organizar una comunidad con aspiraciones democráticas, requiere fortalecer la jerarquía ciudadana por encima de la figura de un elector indolente. Un individuo respaldado en sus derechos sociales y políticos, a modo de brindarle los enseres suficientes para tomar una decisión sustentada al momento de emitir su voto. Es de recuperar la esencia misma de la política, alejándola de las nociones patrimonialistas y clientelares predominantes. Fortaleciendo el interés comunitario, superando la inmediatez del interés privado, transitando de la acción individual a la acción colectiva, refrendando las prácticas de la democracia en favor de las mayorías. 
Juan Mora Heredia é Professor-pesquisador da Universidade Autônoma Metropolitana- Azcapotzalco, Departamento de Sociologia (UAM-Azcapotzalco). Mestre em Sociologia Política pelo Instituto Dr. José María Luis Mora. E-mail: herediajuan57@hotmail.com.

Margarita Jiménez Badillo é Professora-pesquisadora do Instituto Internacional de Estudos Políticos Avançados na Universidade Autônoma de Guerrero, nivel 1 do SNI-Conacyt. Possui doutorado em Ciência Politica e em Administração pela Universidade de Salamanca, na Espanha. E-mail: margaritajimenez_iiepaima@uagro.mx.

\section{Referências}

BANCO MUNDIAL. La violencia juvenil en México: reporte de la situación, el marco legal y los programas gubernamentales. 2012. Disponível em: <http://siteresources.worldbank.org/EXTSOCIALDEVELOPMENT/Resources/244362

1164107274725/3182370-1164110717447/MX-Country-Assessment.pdf>. Acesso em: 10 fev. 2018.

BECERRA, Ricardo; SALAZAR, Pedro; WOLDENBERG, José. La mecánica del cambio político en México. Elecciones, partidos y reformas. Cal y Arena, 2000.

BIZBERG, Ilán. La democracia vacía. In: BIZBERG, Ilán; ZAPATA, Francisco (orgs.). Movimientos Sociales. Los grandes problemas de México, Tomo VI. El Colegio de México, 2010. p. 21-60. Disponível em: <http://cei.colmex.mx/PDFs/Prof\%20Bizberg/Movimientos.pdf>. Acesso em: 10 fev. 2018.

BOBBIO, Norberto. Diccionario de política. Siglo XXI, 1982.

CASTAÑEDA, Jorge. La guerra contra las drogas: John Ehrlichman y lo que México no sabía. Milénio. 28 mar. 2016. Disponível em: <http://www.milenio.com/firmas/jorge_castaneda/guerradrogas-John-Ehrlichman-Mexico_18_709309087.html>. Acesso em: 25 abr. 2017.

CASTELLS, Manuel. La Era de la Información. La Sociedad Red, v. 1, Siglo XXI, 1999. 
CEPAL. Comisión Económica para América Latina y el Caribe. La brecha de la equidad. América Latina, el Caribe y la cumbre social. 1997. Disponível em: <http://www.cepal.org/es/publicaciones/2183-la-brecha-la-equidad-america-latina-caribe-la-cumbresocial>. Acesso em: 16 maio 2017.

Centro de Investigación para el Desarrollo, A.C. (CIDAC). 8 Delitos primero, Índice delictivo. CIDAC. 2015. Disponível em: <http://cidac.org/8-delitos-primero-indice-delictivo-cidac/>. Acesso em: 12 fev. 2018.

CONSEJO NACIONAL DE EVALUACIÓN DE LA POLÍTICA DE DESARROLLO SOCIAL (CONEVAL). Medición multidimensional de la pobreza en México: un enfoque de bienestar económico y de derechos sociales. Disponível em: <http://www.coneval.org.mx/Paginas/busqueda.aspx?k=medicion $\% 20$ multidimensional>. Acesso em: 12 out. 2017.

\section{Memorias del CONEVAL 2006-2016. Disponível em:}

$<$ https://www.coneval.org.mx/InformesPublicaciones/Documents/Memorias/Memorias-Coneval2006-2016.pdf>. Acesso em: 12 fev. 2018.

. Informe de Evaluación de la Política de Desarrollo Social. 2016. Disponível em: <http://www.coneval.org.mx/Medicion/MP/Paginas/Pobreza_2016.aspx>. Acesso em: 12 out. 2017.

DAVID, Paul; FORAY, Dominique. Una introducción a la economía y a la sociedad del saber. Revista Internacional de Ciencias Sociales [online], n. 171, 2002. Disponível em: <www.oei.es/historico/salactsi/david.pdf>. Acesso em: 25 fev. 2018.

DIAMOND, Larry. Elecciones sin democracia. A propósito de los regímenes híbridos. Estudios Políticos, n. 24, p. 117-134, 2004. Disponível em: <http://aprendeenlinea.udea.edu.co/revistas /index.php/estudiospoliticos/article/view/1365/1468>. Acesso em: 25 abr. 2017.

DURAND, Ponte Víctor Manuel. Ciudadanía y cultura política: México 1993-2001. Siglo XXI, 2004

ELIAS, Norbert; SCOTSON, John. Establecidos y marginados. Una investigación sociológica sobre problemas comunitarios. FCE, 2016.

ESCALANTE, Fernando. Homicidios 2008-2009. La muerte tiene permiso. Nexos. 1 jan. 2011. Disponível em: <http://www.nexos.com.mx/?p=14089>. Acesso em: 25 abr. 2017.

ESQUIVEL, Gerardo. Desigualdad extrema en México: Concentración del poder económico y político. OXFAM. 2016. Disponível em: <http://cambialasreglas.org>. Acesso em: 15 out. 2017.

GONZALEZ, Calleja Eduardo. El problema de la violencia: Conceptualización y perspectivas de análisis desde las ciencias sociales. Investigaciones Sociales, v. 10, n. 17, p. 173-216, 2006. Disponível em: <http://revistasinvestigacion.unmsm.edu.pe/index.php/sociales/article/view/7054>. Acesso em: 25 out. 2017.

GUERRERO, Gutiérrez Eduardo. La raíz de la violencia. Nexos. 1 jun. 2011. Disponível em: <https://www.nexos.com.mx/?p=14318>. Acesso em: 11 fev. 2018.

_. La inseguridad 2013-2015. Nexos. 1 jan. 2016. Disponível em: <http://www.nexos.com.mx/?p=27269>. Acesso em: 14 jun. 2017.

INSTITUTO MEXICANO DE ESTUDIOS DE LA CRIMINALIDAD ORGANIZADA, A.C. Todo lo que debería saber sobre el crimen organizado en México. Océano, 1998.

INEGI. INSTITUTO NACIONAL DE ESTADÍSTICA Y GEOGRAFÍA. Encuesta Nacional de Victimización y Percepción sobre Seguridad Pública Principales Resultados (ENVIPE) 2017. 
Disponível em: <http:/www.beta.inegi.org.mx/proyectos/enchogares/regulares/envipe/2017/ default.html>. Acesso em 16: jan. 2018.

. Presentación de resultados de una nueva serie de la Encuesta Nacional de Ingresos y Gastos

de los Hogares (ENIGH) 2016. Comunicado 392/17. Disponível em: <www.inegi.org.mx/saladeprensa/boletines/2017/enigh/enigh_08.pdf>. Acesso em: 11 fev. 2018.

- Presentación de resultados de la Encuesta Nacional sobre Disponibilidad y Uso de las Tecnologías de la Información (ENDUTIH) 2017. Comunicado 105/1. Disponível em: $<$ www.beta.inegi.org.mx/contenidos/saladeprensa/boletines/.../ENDUTIH2018_02.pdf5. Acesso em: 12 fev. 2018.

LA JORNADA. El año más violento fue 2017 con 42 mil homicidios y 12 periodistas asesinados: AI. Disponível em: <http://www.jornada.unam.mx/2018/02/22/politica/015n1pol>. Acesso em: 22 fev. 2018.

LATINOBAROMETRO. Informe $2017 . \quad$ Disponível em: <http://www.latinobarometro.org/latContents.jsp>. Acesso em 10 dez. 2017.

LEVITSKY, Steven; WAY, Lucan. Elecciones sin democracia. El surgimiento del autoritarismo competitivo. Estudios Políticos, n. 24, p. 159-176 enero-junio, 2004. Disponível em: <http://aprendeenlinea.udea.edu.co/revistas/index.php/estudiospoliticos/article/view/1368/1470>. Acesso em: 25 abr. 2017.

LIPSET, Seymour M. El Hombre Político. Las bases sociales de la política. Red Editorial Iberoamericana. 1993.

MARTIN, Devoto Lisandro. Más allá de la alternancia. Relaciones entre partidos políticos en el gobierno y sociedad organizada en México. Tesis Doctoral, FLACSO, agosto, 2013. Disponível em: <http://www.flacso.edu.mx/biblioiberoamericana/TEXT/DOCCS_VIII_promocion_20102013/Devoto_LM.pdf >. Acesso em: 25 fev. 2018.

PEREYRA, Guillermo. México. Violencia criminal y “guerra contra el narcotráfico”. Revista Mexicana de Sociología, v. 74, n. 3, p. 429-460, 2012.

PÉREZ, Correa Catalina. Marcando al delincuente: estigmatización, castigo y cumplimiento del derecho. Revista Mexicana de Sociología, v. 75, n. 2, p. 287-311, 2013.

REYNA, José Luis. Control político, estabilidad y desarrollo en México. Cuadernos del CES n. 3, Colegio de México. 1979.

ROBLES, José Manuel. Ciudadanía digital, introducción a un nuevo concepto de ciudadanos. Editorial UOC, 2009.

SCHEDLER, Andreas. Elecciones sin democracia. El menú de la manipulación electoral. Estudios Políticos, n. 24, p. 137-156, 2004. Disponível em: <http://aprendeenlinea.udea.edu.co/revistas/index.php/estudiospoliticos/article/view/1367/1469>. Acesso em: 25 abr. 2017.

ZAPATA, Francisco. ¿Democratización o rearticulación del corporativismo? El caso de México. Apuntes Electorales Nueva Época, v. 4, n. 17, p. 67-93, 2004. Disponível em: <http://aelectorales.ieem.org.mx/index.php/ae/issue/view/49>. Acesso em: 14 fev. 2018. 
Texto recebido em 11 de agosto de 2017. Aprovado em 14 de novembro de 2017. 